\title{
The conundrum of the young colon cancer patient
}

\section{Citation}

Amri, Ramzi, Liliana G. Bordeianou, and David L. Berger. 2015. "The Conundrum of the Young Colon Cancer Patient." Surgery (August). doi:10.1016/j.surg.2015.07.018.

\section{Published Version}

doi:10.1016/j.surg.2015.07.018

\section{Permanent link}

http://nrs.harvard.edu/urn-3:HUL.InstRepos:23016712

\section{Terms of Use}

This article was downloaded from Harvard University's DASH repository, and is made available under the terms and conditions applicable to Other Posted Material, as set forth at http:// nrs.harvard.edu/urn-3:HUL.InstRepos:dash.current.terms-of-use\#LAA

\section{Share Your Story}

The Harvard community has made this article openly available.

Please share how this access benefits you. Submit a story.

Accessibility 


\title{
The Conundrum of the Young Colon Cancer Patient
}

\author{
Ramzi Amri, MD, Liliana G. Bordeianou, MD and David L. Berger, MD \\ Division of General and Gastrointestinal Surgery, Massachusetts General Hospital and Harvard Medical School, Boston, MA, \\ United States
}

Poster presentation at the $95^{\text {th }}$ annual meeting of the New England Surgical Society

Corresponding author: David. L. Berger, MD, Massachusetts General Hospital, 15 Parkman Street 02114 Boston, MA USA E-mail: dberger@mgh.harvard.edu

\section{Disclosures: none}

This is the final draft post-refereeing. Accepted for publication by Surgery.

The publisher version available at:: http://dx.doi.org/10.1016/j.surg.2015.07.018 


\section{Abstract:}

Background: Colonoscopy has had a major impact on colon cancer incidence and survival for patients who are screened, usually beginning at the age of 50. Meanwhile, the incidence rate of colon cancer is actually increasing in the patients under 50, while no routine screening is implemented for this age group.

Methods: All patients surgically treated for colon cancer (2004-2011) without preexisting highrisk characteristics (HNPCG, IBD) were included (n=1015). Age-related disparities in baseline disease and outcomes were reviewed.

Results: Patients under $50(\mathrm{n}=108 ; 10.6 \%)$ had the highest baseline rates of metastatic $(20.4 \%$ vs. $8.0 \% ; \mathrm{P}<0.001)$, node-positive disease $(54.6 \%$ vs. $39.4 \% ; \mathrm{P}=0.002)$, and higher rates of extramural vascular invasion (38.9 vs. 29.4\%; $\mathrm{P}=0.043)$. Cancer related mortality was also highest in this group (28.7 vs. $18.4 \% ; \mathrm{P}=0.011)$. Multivariable Cox regression shows that patients under 50 are still at significantly higher risk of mortality after adjustment for effects of age, baseline AJCG staging, smoking, and comorbidity (HR: 1.57, 95\% CI 1.01-2.45; P=0.049).

Discussion: Patients under 50 present with the most advanced and aggressive disease, giving them the worst stage-independent prognosis of all age groups. Potential causes include agerelated differences in tumor biology and underdetection by current screening efforts. This raises the question of how to address the conundrum of the young colon cancer patient, who often is the proverbial needle in a haystack of young patients with non-specific gastrointestinal symptoms, but would benefit considerably from early detection. 
The introduction of large scale screening initiatives have played an essential role in the in incidence and mortality had they not been offset by population aging ${ }^{1}$ through a combination of cumulative prevalence and age-related risk. ${ }^{2}$ As age cut-offs are deemed unavoidable to make population-based screening financially and logistically viable, these initiatives have historically focused on the older, high-prevalence population segments. ${ }^{3,4}$ Colorectal screening programs put a lower age boundary for enrollment at 50 years or higher. ${ }^{3,5}$ However, in the last decade the proportion of new colon cancer cases that are diagnosed in patients under 50 years of age grew from about $8 \%$ to an estimate of over $10 \%$ in 2014.7 In fact, patients under 50 are the only demographic with increasing incidence while the overall trend for colon cancer incidence had been showing a steady decrease since the introduction of screening. ${ }^{7, \boldsymbol{g}}$ Recently published data now also project that this age-related disparity is expected to increase further in the future. ${ }^{9}$ Since younger patients usually do not partake in screening initiatives, their diagnosis is reliant on symptomatic presentation, which often leads to delays and misdiagnosis.

This article aims to illustrate and discuss age-related disparities in surgically treated colon cancer patients; an emerging issue that seemingly will continue to grow in magnitude in the coming years. In this paper, we illustrate these disparities through our institution's surgically treated colon cancer cohort and discuss the implications for the treatment of colon cancer.

\section{Methods:}

\section{Patients}

A cohort that included all surgically treated colon cancer patients at Massachusetts General Hospital (MGH) from 2004 through 2011 (n=1071) was extracted from the MGH cancer registry and included in a data repository after institutional review board approval, using 
data from the Research Patient Data Repository, complemented by review of patient records. This data repository was maintained prospectively starting 2011. Due to the significant differences in treatment approach and tumor biology, we exclusively focused on colon cancer and did not include patients with tumors of the rectum. Tumors of the colon were defined as any tumor proximal to the rectosigmoid junction. ${ }^{10}$ Data on long-term outcomes is periodically updated by reviewing patient follow-up records and the social security death index. The last status review of survival and follow-up was on April $1^{\text {st }} 2014$.

For the purposes of this research, we excluded 56 patients with concomitant high-risk diagnoses of hereditary nonpolyposis colon cancer or comorbid inflammatory bowel disease. The included population $(\mathrm{n}=1015)$ was subdivided into age categories meant to form subgroups matching the US screening upper and lower age thresholds. Thus, the groups were under 50 $(\mathrm{n}=108), 50$ to $75(\mathrm{n}=590)$, and over $75(\mathrm{n}=317)$. Comparisons were made to show overall variations between age groups, as well as relative differences of every age group compared to the remainder of the population.

\section{Statistical analysis}

All statistical analysis was performed using SPSS statistical software (IBM Corp. Released 2013. IBM SPSS Statistics for Windows, Version 22.0. Armonk, NY: IBM Corp.). The threshold for statistical significance was set at a two-sided P-value of 0.05. Differences in dichotomous variables were assessed using a chi-square $\left(\chi^{2}\right)$ test. Significance of the differences in continuous variables over all four age groups was performed using a Kruskal-Wallis $\mathrm{H}$ test, while any comparison between a single subgroup and the remainder of the population was performed through a MannWhitney $\mathrm{U}$ test. Lastly, significant differences with a likely multifactorial origin will be assessed in 
multivariable analysis using Cox proportional hazards models, which would allow to compare univariate hazard ratio (HR) and 95\% CI of the events occurring to the multivariable $\mathrm{HR}$ after adjustment for age and stage where relevant, in addition to any relevant covariates encountered that may act as confounders.

\section{Results:}

\section{Presentation characteristics}

A total of 108 patients $(10.6 \%$ of the included group) were under 50 years of age when operated on for colon cancer at our center. These patients presented with lower smoking rates and less comorbidity. Patients under 50 were diagnosed through screening in $9.3 \%$ of cases. The 10 screened young patients were almost exclusively screened either a positive family history $\left(1^{\text {st }}\right.$ degree: 4, $2^{\text {rd }}$-degree: 3). This screening rate was far lower than the $34.7 \%$ diagnosed through screening in patients aged 50-75 $(\mathrm{P}<0.001)$. Previous polyp detection or colorectal cancer diagnoses lowest in patients $<50$ and clearly subject to an age-dependent cumulative effect with the number of patients with a history of polyps more than quadrupling from $3.7 \%$ in patients under 50 to $16.7 \%$ in patients $>75(\mathrm{P}<0.001)$, and the number of patients with a history of colorectal cancer growing from 0 in $<50$ to $4.4 \%$ in $>75(\mathrm{P}=0.002)$. Further details on baseline characteristics can be found in Table $\mathbf{1}$.

\section{Surgical admission and pathology}

Median delay between diagnosis and treatment was shortest in patients $<50$ (18 days, others: 23 days, $\mathrm{P}=0.088$ ), a factor that was demonstrated to be associated with more serious disease in previous work. 11 Patients <50 also had the longest median duration of surgery (<50: 144 minutes vs. others: 124 minutes; $\mathrm{P}=0.003)$ while length of stay incrementally increased by age 
groups $(\mathrm{P}<0.001)$. Readmission, reoperation and perioperative mortality rates did not differ significantly. All admission characteristics are shown in Table 2.

On surgical pathology, as shown in Table 3, a predominance of sigmoid tumors was witnessed in younger patients, which made up 39.8\% of all tumors in patients under 50, compared to $23.8 \%$ in patients older than $50(\mathrm{P}<0.001)$. Statistically significant decreasing trends were noted in age group-specific rates of node-positive disease $(\mathrm{P}=0.009)$, metastatic disease $(\mathrm{P}<0.001)$, and microsatellite instability $(\mathrm{P}<0.001)$. 30-day metastasis rates also were lower in older age groups $(\mathrm{P}<0.001)$. Compared to the remainder of the population, patients $<50$ fared the worst in all of the above-mentioned pathological characteristics, with more cases with tumorpositive nodes (54.6 vs. 39.4\%; RR=1.39, 95\%CI 1.15-1.68; $\mathrm{P}=0.002)$, far more metastatic cases (20.4 vs. $8.0 \%$; $\mathrm{RR}=2.53$, 95\%CI 1.64-3.90; $\mathrm{P}<0.001$ ) as well as higher rates of established metastatic disease within 30 days of the index surgery $(31.4$ vs. $15.7 \%$; RR=2.01; 95\%CI 1.47 2.76; $\mathrm{P}<0.001)$. The pathological characteristics in patients under 50 were also reflected in their rates of extramural vascular invasion (38.9 vs. $29.4 \% ; \mathrm{RR}=1.32,95 \% \mathrm{CI} 1.02-1.71 ; \mathrm{P}=0.043)$ and rates of microsatellite instability (11.1 vs. $2.4 \%$; $\mathrm{RR}=4.57 ; 2.32-8.97 ; \mathrm{P}<0.001)$.

\section{Long-term outcomes and multivariable analysis}

In follow-up, significant differences existed in rates of metastatic disease, being significantly higher in patients $<50(43.5 \% ; \mathrm{HR}=1.80 ; \mathrm{P}<0.001)$, and significantly lower in patients $>75$ $(19.9 \% ; \mathrm{HR}=0.62 ; \mathrm{P}=0.001)$, whereas overall mortality was unsurprisingly highest in patients $>75$ (45.7\%; $\mathrm{P}<0.001)$. However, colon cancer specific mortality was in fact highest in patients $<50(28.7 \%, \mathrm{HR}=1.55 ; \mathrm{P}=0.025)$. More details on long-term outcomes are shown in Table 4. 
Figure 1 demonstrates differences in outcomes between patients under and over 50 in the shape of Cox proportional hazards survival curves. The curves show a univariate increase in hazard ratio $(\mathrm{HR})$ for shorter disease-free survival of $1.80(95 \% \mathrm{CI} 1.31-2.46) \mathrm{P}<0.001$. For mortality, when adjusting for age in order to correct for age-related causes of mortality, the HR of death for patients under 50 is 2.05 (95\% CI 1.31-3.20; $\mathrm{P}=0.002)$. Interestingly, when adjusting further for baseline AJCG staging, current smoking status and colon cancer-adjusted Charlson comorbidity score, the survival difference remains significant (HR: 1.57, 95\% CI 1.001-2.44; $\mathrm{P}=0.049)$

\section{Discussion}

Recent evidence from 35 years of data from the Surveillance, Epidemiology and End Results (SEER) colorectal cancer registry confirms that despite a decreasing trend in the general population, incidence rates are increasing in patients under 50, and are expected to grow even further in the future. ${ }^{9}$ Evidence from our cohort forecasts a scenario where, along with a growth in numbers, patients under 50 will also form a subset with more advanced and more aggressive disease on presentation and subsequently will have the worst outcomes of any age group. If more generalized data confirms what our data illustrates, which is that that young colon cancer patients have an over 50\% relative risk increase of developing metastatic disease and twice the relative hazards of age-standardized mortality, maybe the prevailing approach to forego routine screening of any form for patients under 50 should be re-addressed. If an interplay of advanced and aggressive disease is in fact to blame for the age-related disparities, a combination of late detection and fast progression will need to be addressed in unison. The assumption that early identification and enrollment in screening could solve this issue for certain at-risk groups will also have to be validated in further research as this means 


\section{A challenge to healthcare: further research and policy changes}

The true challenge faced in current as well as future treatment approaches for colon cancer may well lie in the younger tier of the patient population: The young colon cancer patients' age excludes them from routine screening, and unless they are among the small subset of patients identified and screened because of pre-existent high-risk characteristics, their diagnosis will almost invariably be made symptomatically. Worse yet, colon cancer signs and symptoms are mimicked by a spectrum of other gastrointestinal conditions ubiquitous in their age category, ranging from constipation, hemorrhoids and irritable bowel syndrome ${ }^{12}$ to inflammatory bowel disease without concurrent malignancy. ${ }^{13}$ This diagnostic ambiguity is a likely contributor to the more advanced disease younger colon cancer patients presented with.

For evident reasons, it is neither feasible nor desirable to include younger patients indiscriminately in screening initiatives. However, the alarming age-related gap in colon cancer survival between patients over or under 50 years of age shows that a considerable subset of younger patients is still missing out on the benefits of screening. Patients with hereditary colon cancer genotypes, ${ }^{14}$ inflammatory bowel disease, ${ }^{15}$ or primary sclerosing cholangitis ${ }^{16}$ are clear and well-established choices for earlier and more rigorous surveillance that cross age boundaries, and fortunately, in many cases, these patients are shown to be under adequate care and to have reaped the benefit of screening $\mathbf{1 6 , 1 7}$ and show that identifying the right subset of patients and enrolling them in screening initiative can level the playing field and give them equivalent survival and quality of life.

The issue now lies in the patients currently identified as sporadic--those that do not fall in any of the known high-risk categories, and thus begin screening when they reach 50 years of age. Unfortunately, these sporadic cases form the majority of colon cancer patients under 50 and are 
the core of the issue at hand. Far more effort is needed to find new targets for earlier screening. Ethnicity could potentially be an important starting point. The American College of Gastroenterologists has already called for a lowering of the recommended screening age in African-Americans to 45 in $2005,{ }^{18}$ and recent cohort data from our center still shows that despite universal access to care in Massachusetts, ethnic minorities are still less likely to get screened and still present with more advanced disease at a younger age. 19

Additionally, as current efforts to identify high-risk genetic profiles for colon cancer are getting more concrete and provide reproducible and clinically meaningful results, 20 a translational effort towards genetic profiling could also play an important role in the future to identify younger high-risk patients who would benefit the most from screening. Subsequently, tailored interventions currently used to increase screening compliance in carriers of high-risk genetic profiles may also be used to achieve timely enrollment. ${ }^{21}$

\section{Relevance, limitations and counterarguments}

The preexisting body of work on age disparities highlighted many facets of the issue of young-onset colon cancer, most often separately focusing on either incidence, ${ }^{8,9}$ stage, ${ }^{22}$, or overtreatment. ${ }^{23}$ These works usually use population data like NGI SEER, which doesn't provide the same level of detail that a cohort study can provide on baseline characteristics, more subtle pathologic and admission characteristics and disease-specific mortality. To our knowledge, this is the first paper that comprehensively covers the full scope of the various issues related to youngonset surgically treated colon cancer in a single cohort from baseline presentation and admission characteristics to surgical pathology and long-term outcomes. Selecting a large, complete and unbiased population sample, careful evaluation of baseline characteristics during the 
interpretation of results, and focusing on cancer-specific outcomes were important ways to keep bias and risk of erroneous interpretation to a minimum. However these points remain based on a single cohort and will need conformation in larger population-based studies. Some of the contrast shown may also be inherent to age itself as a factor: For example, lower cancer-related death rates with age could be in part due to older patients dying from other reasons or from comorbid disease where colon cancer is not the sole culprit. Similarly, it is quite possible that higher mortality in younger patients is really in some aspects due to lower mortality in older patients, who may have slower-growing tumors.

A central element of any discussion about the expansion of screening initiatives is costs. If the routine screening age would be lowered, the cost would be substantial. Cost-effectiveness analysis specifically focused on younger patients will need to evaluate the relative merits of screening modalities in various combinations and time intervals, as was done initially for the current screening age range. Research on cost-estimates for colorectal has historically been focused on patients over 50 and have presented a cost of about US $\$ 10.000$ to 25.000 per life year saved. ${ }^{24}$ More recent studies have focused mostly on reviewing the cost effectiveness of current screening standards, ${ }^{25}$ making these cost models are hard to extrapolate to younger patients. Although in general, it follows to assume the relative low a priori odds of finding a tumor will put pressure on cost-effectiveness and increase chances of false positives. On the other hand, these factors may be offset by the potential gain in life-years and working years. With this in mind, the younger population may be an adequate target to test and validate novel cost-effective low-threshold mass screening modalities, the most important of which may be the fecal immunochemical tests (FIT) ${ }^{26}$ and, provided it eventually becomes considerably more affordable, multi-target stool DNA testing. ${ }^{27}$ Another rapid and noninvasive possibility would be to use CT colonography as a screening method, but this raises the issue of radiation exposure, which potentially has more consequences in younger patients. ${ }^{28}$ With 
the predominance of distal tumors witnessed in younger patients, and considering the higher rates of metastasis and mortality in sigmoid tumors previously demonstrated, ${ }^{29}$ there may be a role for recommending sigmoidoscopy in this age group which would clearly be significantly less costly than recommending a full colonoscopy.

\section{Conclusions}

With current practice identifying only some of the younger at-risk future colon cancer patients and screening them adequately, the conundrum of the young colon cancer patient lies in those patients that currently do not have an evident risk factor. These young patients are not routinely screened and subsequently present far later, with symptomatic and often advanced and aggressive disease, leading to poorer outcomes. These patients are inherently hard to recognize due to the low à priori odds of their eventual diagnosis. The challenge lies in finding new ways to identify those young at risk patients. Cost-effectiveness needs to be kept in mind, and is most likely achievable if larger population studies identify factors distinguishing those at risk for young-onset colon cancer out of a vast number of patients with similar symptoms who do not harbor a malignancy. As long as we are not able to timely identify and screen them, younger colon cancer patients are likely to remain at a disadvantage. 
Table 1. Baseline characteristics at presentation

\begin{tabular}{|c|c|c|c|c|c|}
\hline & \multicolumn{5}{|c|}{ Age Categories } \\
\hline & Overall & $<50$ & $50-75$ & $>75$ & $\mathbf{P}$ \\
\hline & $N=1015$ & $N=108$ & $N=590$ & $N=317$ & \\
\hline \multicolumn{6}{|l|}{ General } \\
\hline Age (median, IQR) & $67(21)$ & $44(8)^{\star \star \star}$ & $64(12)^{\star \star \star}$ & $82(8)^{\star \star \star}$ & $<0.001$ \\
\hline BMI (median, IQR) & $26.6(7.7)$ & $26.8(7.9)$ & $27.8(8)^{\star \star \star}$ & $24.9(5.7)^{\star \star \star}$ & $<0.001$ \\
\hline Male (\%) & 50.6 & 48.1 & $53.7^{\star}$ & $45.7^{\star}$ & 0.062 \\
\hline Minority patients (\%) & 10.4 & 13.0 & $12.4^{*}$ & $6.0^{\star *}$ & 0.007 \\
\hline \multicolumn{6}{|l|}{$\begin{array}{c}\text { Comorbidity, Lifestyle and } \\
\text { History }\end{array}$} \\
\hline History of Polyps (\%) & 12.5 & $3.7^{\star \star}$ & 11.9 & $16.7^{\star \star}$ & 0.001 \\
\hline Personal history of CRC (\%) & 2.5 & 0 & $1.4^{\star}$ & $4.4^{\star \star}$ & 0.003 \\
\hline First-degree relative CRC (\%) & 11.4 & 9.3 & 11.4 & 12.3 & 0.69 \\
\hline ASA (mean, SD) & $2.37 \pm 0.60$ & $2.06 \pm 0.54^{\star \star \star}$ & $2.32 \pm 0.59^{\star \star}$ & $2.57 \pm 0.57^{\star \star \star}$ & $<0.001$ \\
\hline Charlson (mean, SD) & $0.73 \pm 1.20$ & $0.26 \pm 0.74^{\star \star \star}$ & $0.68 \pm 1.21^{* *}$ & $1.00 \pm 1.22^{\star \star \star}$ & $<0.001$ \\
\hline Alcohol - social (\%) & 55.9 & 62.0 & $58.8^{\star}$ & $48.3^{\star \star}$ & 0.004 \\
\hline Alcohol - ever abuse (\%) & 7.9 & 4.6 & $9.8^{\star \star}$ & $5.4^{\star}$ & 0.024 \\
\hline Smoking - ever (\%) & 53.2 & $28.7^{\star \star \star}$ & $58.0^{\star \star \star}$ & 52.7 & $<0.001$ \\
\hline Smoking - current (\%) & 12.2 & 11.1 & $14.4^{\star \star}$ & $7.6^{\star \star}$ & 0.005 \\
\hline Inflammatory bowel disease (\%) & 3.5 & $8.8^{\star \star}$ & 3.9 & $0.9^{\star \star}$ & $<0.001$ \\
\hline $\operatorname{HNPCC}(\%)^{a}$ & 1.8 & $5.6^{\star \star}$ & 1.4 & 0.9 & 0.002 \\
\hline \multicolumn{6}{|l|}{ Cancer presentation } \\
\hline Screening diagnosis (\%) & 26.5 & $9.3^{\star \star \star}$ & $34.7^{\star \star \star}$ & $17.0^{\star \star \star}$ & $<0.001$ \\
\hline Emergency presentation (\%) & 9.9 & 7.4 & 10.6 & 10.4 & 0.653 \\
\hline CEA measured & 58.0 & $67.6^{\star}$ & 56.6 & 58.0 & 0.104 \\
\hline CEA (median, IQR) ${ }^{a}$ & $3.3(8.7)$ & $2.7(10.9)$ & $3.1(9.0)$ & $3.6(7.7)$ & 0.405 \\
\hline Neoadjuvant chemo (\%) & 3.3 & $10.2^{\star \star \star}$ & 3.6 & $0.6^{\star \star}$ & $<0.001$ \\
\hline \multicolumn{6}{|c|}{ 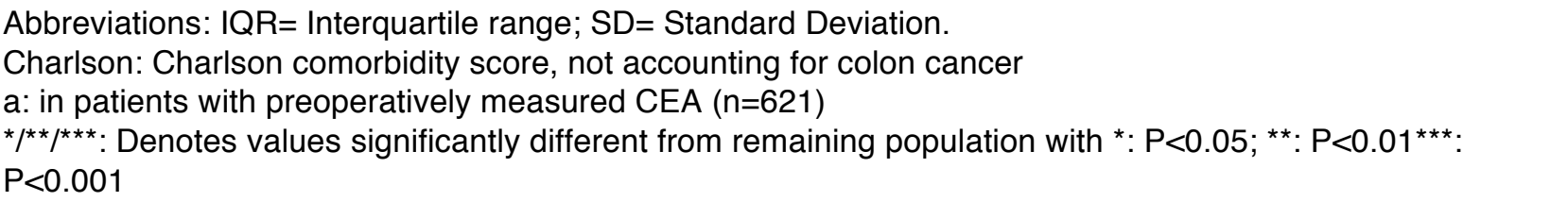 } \\
\hline
\end{tabular}

Dichotomous outcomes expressed as percentages were compared using a chi-square coefficient. Difference of continuous values expressed as means or medians were compared using a KruskalWallis test to assess for statistical significance between the three age categories, and using a MannWhitney $U$ test to compare an age category with the remainder of the population. 
Table 2. Admission characteristics

\begin{tabular}{|c|c|c|c|c|c|}
\hline & & $\mathbf{A g}$ & Categorie & & \\
\hline & Overall & $<50$ & $50-75$ & $>75$ & $\mathbf{P}$ \\
\hline Diagnosis-to-treatment, days (median, IQR) & $22(27)$ & $18(21)$ & $24(28)^{\star \star}$ & $21(30)$ & 0.021 \\
\hline Stay duration, days (median, IQR) & $5(4)$ & $4(3)$ & $4(4)^{\star \star \star}$ & $6(5)^{\star \star \star}$ & $<0.001$ \\
\hline Surgery duration, minutes (median, IQR) & $126(101)$ & $144(93)^{\star \star}$ & $130(110)$ & $110(84)^{\star \star \star}$ & $<0.001$ \\
\hline Laparoscopic procedure (\%) & 26.0 & 33.3 & 28.0 & $19.9^{\star \star}$ & 0.006 \\
\hline Conversion rate $(\%)^{a}$ & 13.8 & 10.3 & 15.4 & 11.6 & 0.70 \\
\hline 30-day readmission (\%) & 7.6 & 6.5 & 7.6 & 7.9 & 0.89 \\
\hline 30-day reoperation (\%) & 2.9 & 3.7 & 3.2 & 1.9 & 0.45 \\
\hline 30 -day death rate $(\%)$ & 1.6 & 0.9 & 1.2 & 2.5 & 0.26 \\
\hline $\begin{array}{l}{ }^{a} \text { in laparoscopic procedures }(n=195) \\
\star / /^{* \star} / \star \star \star \\
P<0.001 \text { : (in bold) }\end{array}$ & . & . & 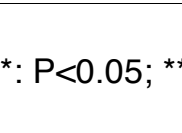 & $P<0.01^{\star * \star}:$ & \\
\hline
\end{tabular}


Table 3. Surgical pathology

\begin{tabular}{|c|c|c|c|c|c|c|c|c|}
\hline & \multicolumn{8}{|c|}{ Age Categories } \\
\hline & Overall & $<50$ & RR (95\%Cl) & $50-75$ & RR (95\%Cl) & $>75$ & RR (95\%Cl) & $\mathbf{P}$ \\
\hline \multicolumn{9}{|l|}{ Primary disease site } \\
\hline Left colon & 12.0 & 15.7 & $1.36(0.85-2.18)$ & 13.2 & $1.28(0.90-1.81)$ & $8.5^{\star}$ & $0.63(0.42-0.94)$ & 0.052 \\
\hline Right colon & 52.9 & $35.2^{\star \star \star}$ & $0.64(0.49-0.83)$ & $49.5^{\star}$ & $0.86(0.77-0.96)$ & $65.3^{\star \star \star}$ & $1.38(1.24-1.55)$ & $<0.001$ \\
\hline Sigmoid & 25.5 & $39.8^{\star \star \star}$ & $1.67(1.29-2.17)$ & $28.1^{*}$ & $1.29(1.03-1.60)$ & $15.8^{\star \star \star}$ & $0.53(0.40-0.70)$ & $<0.001$ \\
\hline $\mathrm{N}+$ disease $(\%)$ & 41.0 & $54.6^{\star \star}$ & $1.39(1.15-1.68)$ & 40.0 & $0.94(0.81-1.09)$ & 38.3 & $0.91(0.77-1.07)$ & 0.009 \\
\hline M+ disease (\%) & 9.4 & $20.4^{\star \star \star}$ & $2.53(1.64-3.90)$ & 9.0 & $0.91(0.62-1.34)$ & $6.3^{*}$ & $0.59(0.37-0.94)$ & $<0.001$ \\
\hline 30-day metastasis (\%) & 17.3 & $31.5^{\star \star \star}$ & $2.01(1.47-2.76)$ & 18.1 & $1.12(0.85-1.47)$ & $11.0^{\star \star \star}$ & $0.55(0.39-0.77)$ & $<0.001$ \\
\hline High-grade (\%) & 18.9 & 16.2 & $0.84(0.53-1.33)$ & 18.0 & $0.89(0.68-1.17)$ & 21.5 & $1.22(0.92-1.60)$ & 0.35 \\
\hline EMVI (\%) & 30.4 & $38.9^{\star}$ & $1.32(1.02-1.71)$ & 28.7 & $0.88(0.73-1.06)$ & 30.6 & $1.01(0.83-1.23)$ & 0.11 \\
\hline MSI (\%) & 3.4 & $11.1^{\star \star \star}$ & $4.57(2.32-8.97)$ & $2.4^{*}$ & $0.51(0.26-0.99)$ & 2.5 & $0.68(0.31-1.48)$ & $<0.001$ \\
\hline
\end{tabular}


Table 4. Long-term outcomes

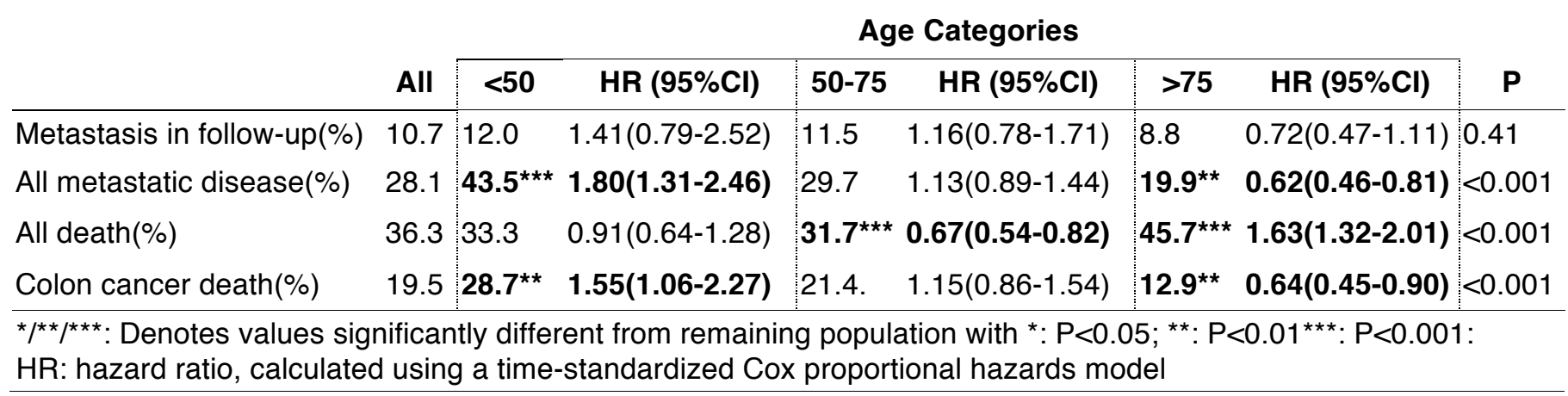


Figure 1. Cox proportional hazards models comparing survival and disease-free survival for patients over and under 50 years
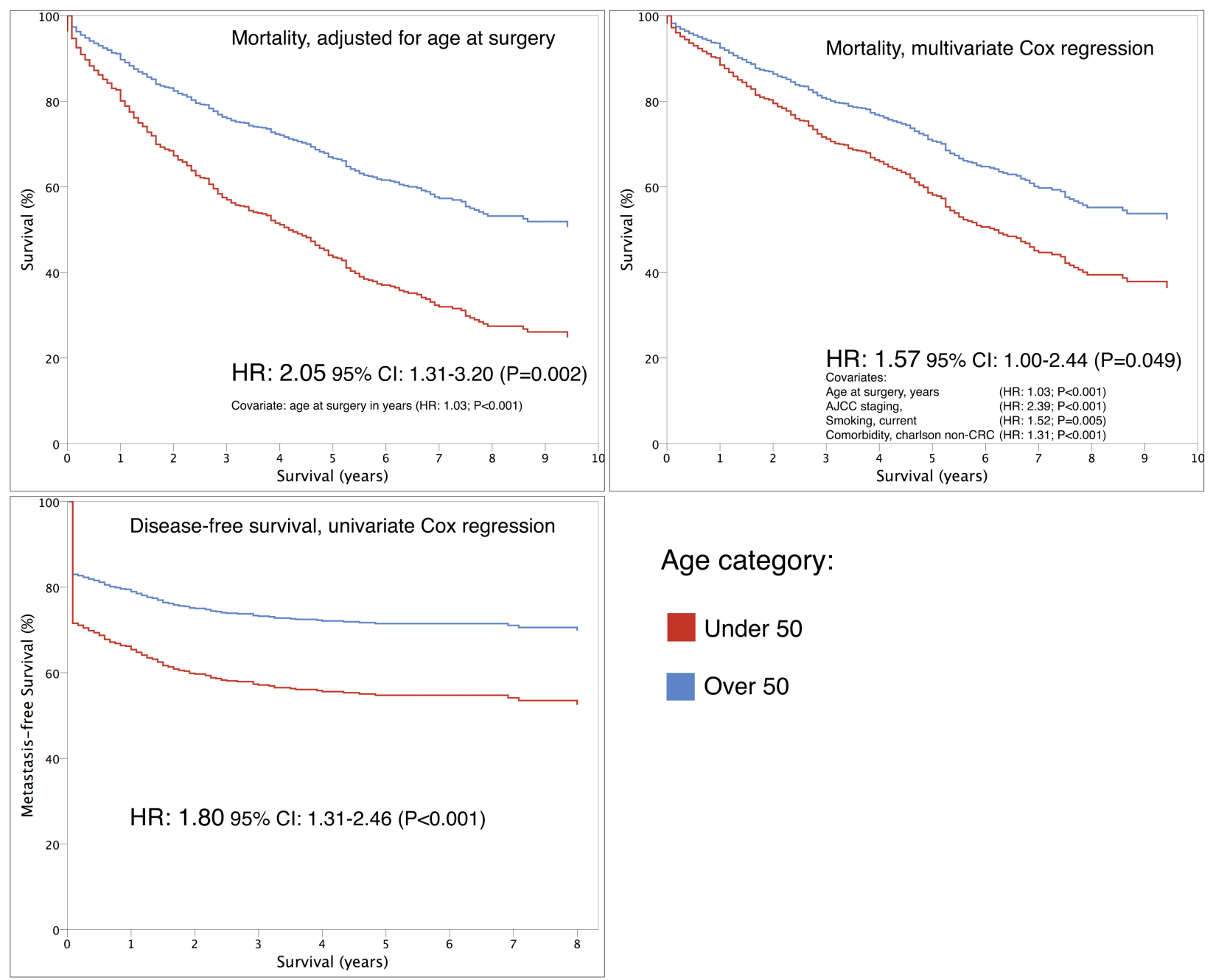

Age category:

Under 50

Over 50 


\section{Acknowledgements:}

This work was conducted with support from Harvard Catalyst | The Harvard Clinical and Translational Science Centre (National Centre for Research Resources and the National Centre for Advancing Translational Sciences, National Institutes of Health Award 8UL1TR000170-05 and financial contributions from Harvard University and its affiliated academic health care centres). The content is solely the responsibility of the authors and does not necessarily represent the official views of Harvard Catalyst, Harvard University and its affiliated academic health care centres, or the National Institutes of Health.) This work was also supported by the Dutch Cancer Society, the Dutch Digestive Society, the Amsterdam University Funds and the Fulbright Foundation.

Author Contributions: Dr. Berger had full access to all the data in the study and takes responsibility for the integrity of the data and the accuracy of the data analysis. Study concept and design: Amri and Berger. Acquisition of data: Amri and Berger. Analysis and interpretation of data: Amri and Berger. Drafting of the manuscript: Amri and Berger. Critical revision of the manuscript for important intellectual content: Amri, Bordeianou, Sylla and Berger. Statistical analysis: Amri. Obtained funding: Amri and Berger. Administrative, technical, and material support: Amri, Bordeianou, Sylla and Berger. Study supervision: Berger.

Financial Disclosure: None.

Previous Presentation: This paper was presented at the 95th Annual Meeting of the New England Surgical Society in poster format; September 12-14, 2014; Stowe, Vermont 


\section{REFERENGES}

1. Yancik R. Population aging and cancer: a cross-national concern. Cancer $\mathcal{F}$. 2005;1 1(6):437-441.

2. Umeto H, Yoshida T, Araki K, Yagishita H, Mikami T, Okayasu I. Appearance of epithelial and stromal genomic instability in background colorectal mucosa of sporadic colorectal cancer patients: relation to age and gender. 7 Gastroenterol. 2009;44(10):10361045.

3. UK Colorectal Cancer Screening Pilot Group. Results of the first round of a demonstration pilot of screening for colorectal cancer in the United Kingdom. BMF. 2004;329(7458):133.

4. U.S. Preventive Services Task Force. Screening for colorectal cancer: recommendation and rationale. Ann Intern Med. 2002;137(2):129-131.

5. Levin B, Lieberman DA, McFarland B, et al. Screening and surveillance for the early detection of colorectal cancer and adenomatous polyps, 2008: a joint guideline from the American Cancer Society, the US Multi-Society Task Force on Colorectal Cancer, and the American College of Radiology. CA Cancer 7 Clin. 2008;58(3):130-160.

6. Fairley TL, Cardinez CJ, Martin J, et al. Colorectal cancer in U.S. adults younger than 50 years of age, 1998-2001. Cancer. 2006;107(5 Suppl):1153-1161.

7. Siegel R, Desantis C, Jemal A. Colorectal cancer statistics, 2014. CA Cancer 7 Clin. 2014;64(2):104-117.

8. O'Connell JB, Maggard MA, Liu JH, Etzioni DA, Livingston EH, Ko CY. Rates of colon and rectal cancers are increasing in young adults. Am Surg. 2003;69(10):866-872.

9. Bailey CE, Hu C-Y, You YN, et al. Increasing Disparities in the Age-Related Incidences of Colon and Rectal Cancers in the United States, 1975-2010. FAMA Surg. 2014:1-6.

10. Li M, LiJY, Zhao AL, Gu J. Colorectal cancer or colon and rectal cancer? Clinicopathological comparison between colonic and rectal carcinomas. Oncology. 2007;73(1-2):52-57.

11. Amri R, Bordeianou LG, Sylla P, Berger DL. Treatment Delay in Surgically-Treated Colon Cancer: Does It Affect Outcomes? Ann Surg Oncol. 2014.

12. Cash BD, Schoenfeld P, Chey WD. The utility of diagnostic tests in irritable bowel syndrome patients: a systematic review. Am $\mathcal{F}$ Gastroenterol. 2002;97(11):2812-2819.

13. Weedon DD, Shorter RG, Ilstrup DM, Huizenga KA, Taylor WF. Crohn's disease and cancer. $\mathcal{N}$ Engl J Med. 1973;289(21):1099-1103.

14. Mesher D, Dove-Edwin I, Sasieni P, et al. A pooled analysis of the outcome of prospective 
colonoscopic surveillance for familial colorectal cancer. Int f Cancer. 2014;134(4):939-947.

15. Shergill AK, Farraye FA. Toward a consensus on endoscopic surveillance of patients with colonic inflammatory bowel disease. Gastrointest Endosc Clin N Am. 2014;24(3):469-481.

16. Boonstra K, Weersma RK, van Erpecum KJ, et al. Population-based epidemiology, malignancy risk, and outcome of primary sclerosing cholangitis. Hepatology.

2013;58(6):2045-2055.

17. Annese V, Daperno M, Rutter MD, et al. European evidence based consensus for endoscopy in inflammatory bowel disease. In: Vol 7. 2013:982-1018.

18. Agrawal S, Bhupinderjit A, Bhutani MS, et al. Colorectal cancer in African Americans. Am $\mathcal{J}$ Gastroenterol. 2005;100(3):515-23-discussion 514.

19. Amri R, Stronks K, Bordeianou LG, Sylla P, Berger DL. Gender and ethnic disparities in colon cancer presentation and outcomes in a US universal health care setting. 7 Surg Oncol. 2014 .

20. Zhang B, Jia W-H, Matsuda K, et al. Large-scale genetic study in East Asians identifies six new loci associated with colorectal cancer risk. Nat Genet. 2014;46(6):533-542.

21. Lowery JT, Horick N, Kinney AY, et al. A randomized trial to increase colonoscopy screening in members of high-risk families in the colorectal cancer family registry and cancer genetics network. Cancer Epidemiol Biomarkers Prev. 2014;23(4):601-610.

22. You YN, Xing Y, Feig BW, Chang GJ, Cormier JN. Young-onset colorectal cancer: is it time to pay attention? Arch Intern Med. 2012;172(3):287-289.

23. Kneuertz PJ, Chang GJ, Hu C-Y, et al. Overtreatment of Young Adults With Colon Cancer: More Intense Treatments With Unmatched Survival Gains. FAMA Surg. 2015.

24. Pignone M, Saha S, Hoerger T, Mandelblatt J. Cost-effectiveness analyses of colorectal cancer screening: a systematic review for the U.S. Preventive Services Task Force. Ann Intern Med. 2002;137(2):96-104.

25. Lansdorp-Vogelaar I, Knudsen AB, Brenner H. Cost-effectiveness of colorectal cancer screening - an overview. Best Pract Res Clin Gastroenterol. 2010;24(4):439-449.

26. Quintero E, Castells A, Bujanda L, et al. Colonoscopy versus fecal immunochemical testing in colorectal-cancer screening. $\mathcal{N}$ Engl J Med. 2012;366(8):697-706.

27. Imperiale TF, Ransohoff DF, Itzkowitz SH, et al. Multitarget stool DNA testing for colorectal-cancer screening. $\mathcal{N}$ Engl $\mathcal{J}$ Med. 2014;370(14):1287-1297.

28. de Haan MC, Pickhardt PJ, Stoker J. CT colonography: accuracy, acceptance, safety and position in organised population screening. Gut. 2015;64(2):342-350.

29. Amri R, Bordeianou LG, Sylla P, Berger DL. Variations in Metastasis Site by Primary 
Location in Colon Cancer. 7 Gastrointest Surg. 2015. 